\title{
$P$ elements and $P-M$ characteristics in natural populations of Drosophila melanogaster in the southernmost islands of Japan and in Taiwan
}

\author{
MASANOBU ITOH* $†$, NOBUHIRO SASAI $\uparrow$, YUTAKA INOUE $\dagger \&$ \\ MASAYOSHI WATADA§ \\ $\dagger$ Department of Applied Biology, Kyoto Institute of Technology, Sakyo-ku, Kyoto 606-8585, Japan, $¥$ Osaka \\ University of Foreign Studies, Minoo, Osaka 562-0022, Japan and §Department of Biology \& Earth Sciences, \\ Ehime University, Matsuyama 790-8577, Japan
}

\begin{abstract}
In order to study $\mathrm{P}$ element dynamics in natural populations of Drosophila melanogaster, 126 isofemale lines were examined from seven of the southernmost islands of Japan (the Sakishima Islands) and from Taiwan. Gonadal dysgenesis (GD) tests showed large divergences in the P-M phenotypes ( $\mathrm{P}$ inducing and $\mathrm{P}$ repressing abilities) between the island populations. The P-M characteristics of each population, however, had not greatly changed in the past 15 years. Their genomic P element profiles are highly similar, consisting mostly of full-size P and of KP elements. We found no clear relationship between phenotype and genomic $\mathrm{P}$ element composition.
\end{abstract}

Keywords: Drosophila melanogaster, KP element, P element, P-M system, Sakishima Islands, Taiwan.

\section{Introduction}

$\mathrm{P}$ transposable elements are responsible for P-M hybrid dysgenesis in Drosophila melanogaster (Kidwell et al., 1977; Bingham et al., 1982; Rubin et al., 1982; O'Hare \& Rubin, 1983; see also review by Engels, 1996). They are thought to have been introduced recently to D. melanogaster from another Drosophila species by a horizontal transmission (the recent-invasion hypothesis: Kidwell (1983), Anxolabéhère et al. (1988) and Houck et al. (1991)). P element transposition is primarily regulated by the production of transposase in germ line cells (Karess \& Rubin, 1984; Laski et al., 1986; Rio et al., 1986). The $66 \mathrm{kDa}$ repressor protein suppresses transposase production and is partly maternally transmitted (P cytotype (Engels, 1979; Misra et al., 1993; Rasmusson et al., 1993)). Full-size (autonomous) P elements encode both transposase and repressor. Fullsize $\mathrm{P}$ elements and elements with some specific deletions are called type I repressor elements (Gloor et al., 1993) because of encoding the repressor or a similar polypeptide. In addition, elements with larger deletions and a biparentally transmitted repression ability are called

*Correspondence. E-mail: mitoh@ipc.kit.ac.jp
Type II repressor elements, and include the KP element (Black et al., 1987; Jackson et al., 1988; Andrew \& Gloor, 1995). The activity of a $\mathrm{P}$ element has been shown to be sensitive to its genomic position (Robertson \& Engels, 1989; Gloor et al., 1993; Misra et al., 1993; Rasmusson et al., 1993). Involvement of some other regulatory mechanisms is suspected and this is under study (see Simmons et al., 1996).

Surveys of genomes of wild populations also shed light on $\mathrm{P}$ element regulation (Todo et al., 1984; Anxolabéhère et al., 1985, 1988, 1990; Sakoyama et al., 1985; Biémont et al., 1990; Gamo et al., 1990; Matsuura et al., 1993; Corish et al., 1996; Hu \& Wang, 1998; Bonnivard \& Higuet, 1999; Hatano et al., 1999). Genomic P element composition and its relationship to $\mathrm{P}-\mathrm{M}$ phenotypes was extensively examined in eastern Australian wild populations, among which a geographical cline in P-M phenotype found in the 1980s had decayed by the early 1990s (Boussy, 1987; Boussy \& Kidwell, 1987; Boussy et al., 1988, 1998; French et al., 1999). All isofemale lines created in the 1990s had many $\mathrm{P}$ element copies, which were mostly full-size $\mathrm{P}$ and $\mathrm{KP}$ elements. No clear difference was detected in genomic $\mathrm{P}$ element profiles among $\mathrm{P}, \mathrm{Q}$, and $\mathrm{M}^{\prime}$ lines, nor between lines showing maternally or biparentally transmitted 
repression, but a weak correlation was seen between the relative numbers of full-size $\mathrm{P}$ and of KP elements $(\mathrm{KP} / \mathrm{P}$ ratio) and $\mathrm{P}$ activity (Itoh et al., 1999). On the other hand, Bonnivard \& Higuet (1999) reported a phenotypic stability in the P-M system in a wide region covering Eurasia, Africa and Oceania. They also demonstrated a correlation between the relative numbers of full-size P and of KP elements in the genome and P-M characteristics.

In the D. melanogaster populations in and around Japan, Matsuura et al. (1993) surveyed GD characters and reported the absence of a geographical cline in their phenotypes and the predominance of Q strains. In order to study $\mathrm{P}$ element dynamics in natural populations of D. melanogaster, we focused on the P-M phenotypes (both the $\mathrm{P}$ inducing and the $\mathrm{P}$ repressing abilities) of some strains from the southernmost islands of Japan, the Sakishima Islands, where some strong $\mathrm{P}$ type isofemale lines were found, in addition to many $\mathrm{Q}$ lines (Matsuura et al., 1993). Here we show that the $\mathrm{P}$ element-associated phenotypes have not greatly changed in the past 15 years in this area. Genomic P element profiles were highly homogeneous and full-size $\mathrm{P}$ and KP elements were the only two major size classes of $\mathrm{P}$ elements seen in the genomes. The causal bases of P-M phenotypes and the dynamics of $\mathrm{P}$ elements in small island populations are discussed under the theory of recent invasion.

\section{Materials and methods}

\section{Flies}

Drosophila melanogaster wild flies were collected using banana traps in seven Sakishima islands from 1997 to 1999 (Table 1). After collection, inseminated females were kept individually in vials to establish isofemale lines. Isofemale lines of Taipei established in 1996 (TP lines) were kindly provided by S.-C. Tsaur. In total, 126 isofemale lines were used. Flies were maintained on standard food medium at $25^{\circ} \mathrm{C}$ except for the cross for the GD test (see below).

\section{Gonadal dysgenesis (GD) tests and definition of lines}

With Harwich and Canton $\mathrm{S}$ as $\mathrm{P}$ and $\mathrm{M}$ standards, respectively, two kinds of crosses, A (Canton $\mathrm{S}$ females $\times$ tested males) and $\mathrm{A}^{*}$ (tested females $\times$ Harwich males), were performed at $29^{\circ} \mathrm{C}$ (Kidwell et al., 1977; Engels \& Preston, 1980). All $\mathrm{F}_{1}$ females were individually dissected and the GD score for each line was calculated as the percentage of undeveloped ovaries. More than $50 \mathrm{~F}_{1}$ females were dissected for each cross. P-M characteristics were defined as in Kidwell (1983); $\mathrm{P}$ strain $(>10 \%$ GD in cross A and $<10 \%$ GD in cross $\left.\mathrm{A}^{*}\right)$, Q strain ( $<10 \%$ GD in both crosses $\mathrm{A}$ and $\left.\mathrm{A}^{*}\right)$, and $\mathrm{M}\left(<10 \%\right.$ GD in cross $\mathrm{A}$ and $>10 \%$ GD in cross $\left.\mathrm{A}^{*}\right)$, and Quesneville \& Anxolabéhère (1998); $\mathrm{P}^{\prime}$ (>10\% in both crosses $\mathrm{A}$ and $\mathrm{A}^{*}$ ) (Fig. 1). A phenotypic $\mathrm{M}$ line with $\mathrm{P}$ sequences in the genome is an $\mathrm{M}^{\prime}$ (Rubin et al., 1982).

\section{Genomic DNA and Southern blot hybridization}

Fly genomic DNA was extracted from 10 adults using standard methods. For Southern blot hybridization, genomic DNA was digested with DdeI and probed by the $D d e \mathrm{I}-B$ siWI 189 bp fragment in the plasmid $\mathrm{p} \pi 25.1$ (Itoh et al., 1999). Hybridization was performed using standard methods. This hybridization system can detect full-size $\mathrm{P}$ elements as a $2.2-\mathrm{kb}$ band and each of many defective elements as a band of specific length, for example, KP elements as a $0.4-\mathrm{kb}$ band.

\section{Quantification of genomic $P$ elements}

Scanning densitometry was performed by scanning the autoradiographs of the Southern blots, then analysing the scanned image with computer software, NIH IMAGE ver. 1.60. Equimolar amounts of the restriction fragments from full-size P and KP elements should generate equal density bands on the blots, because the probe hybridizes to an internal region of the expected DdeI restriction fragments from both elements (Itoh et al.,
Table 1 Populations of Drosophila melanogaster examined and their $\mathrm{KP} / \mathrm{P}$ ratios

\begin{tabular}{llccc}
\hline Symbol & \multicolumn{1}{c}{ Locality } & Collection date & KP/P ratio \pm SD & No. of lines \\
\hline TP & Taipei, Taiwan & Dec. 1996 & $2.26 \pm 1.28$ & 20 \\
YN & Yonaguni & Dec. 1998 & $1.23 \pm 0.46$ & 10 \\
HT & Hateruma & Dec. 1998 & $1.18 \pm 0.36$ & 12 \\
IR & Iriomote & Nov. 1998 & $0.71 \pm 0.14$ & 24 \\
IS & Ishigaki & Oct. 1997 & $2.25 \pm 0.64$ & 13 \\
IB & Irabu & Mar. 1999 & $1.68 \pm 0.38$ & 11 \\
KR & Kurima & Mar. 1999 & $4.15 \pm 1.08$ & 15 \\
MY & Miyako & Mar. 1999 & $2.37 \pm 0.87$ & 21 \\
\hline
\end{tabular}




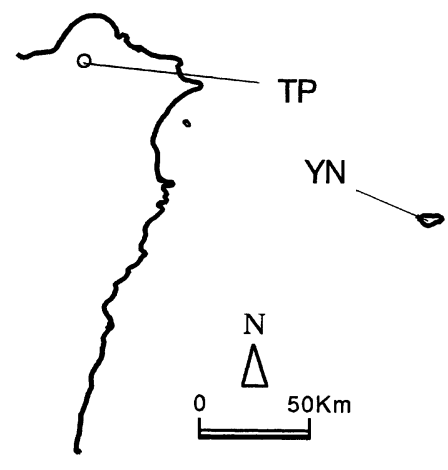

HT
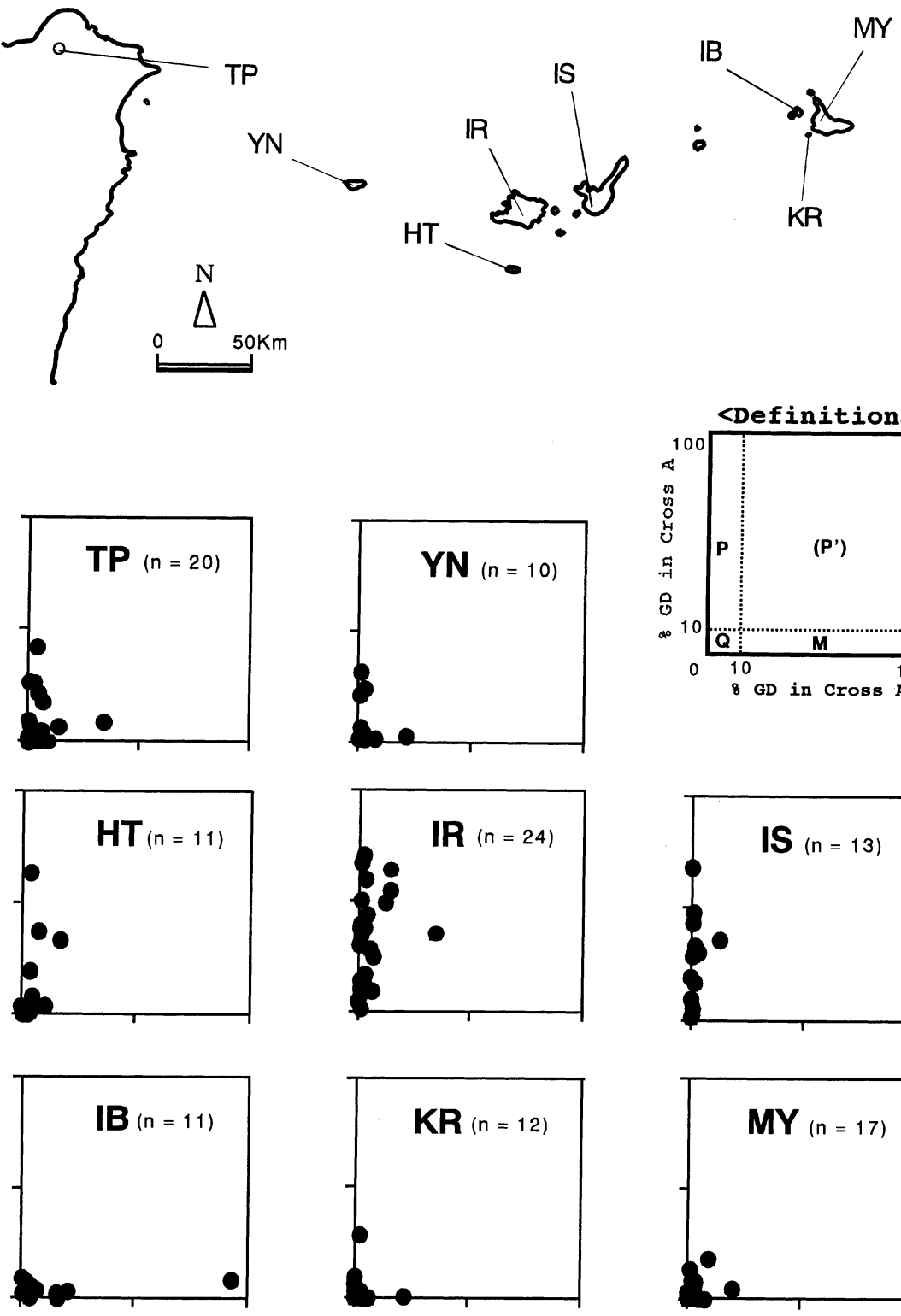
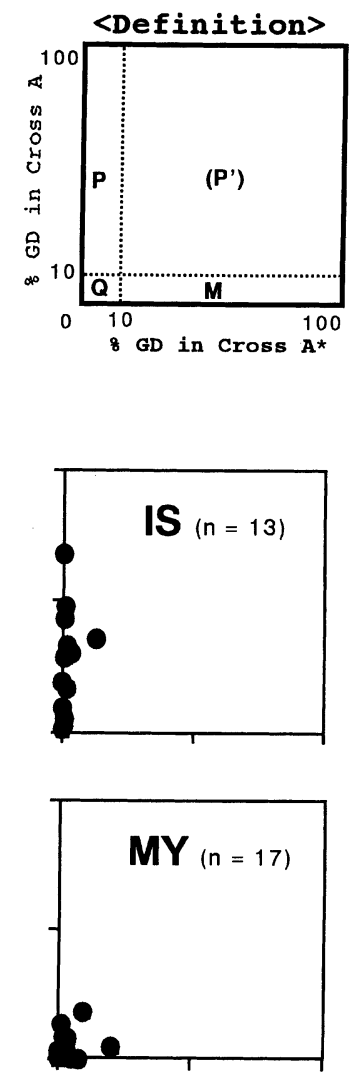

Fig. 1 The results of GD tests for populations from the Sakishima Islands and Taipei. (A) Collection sites. Abbreviations of collecting sites are shown in Table 1. The location of Ishigaki island is $24.3^{\circ} \mathrm{N}$ latitude and $124.2^{\circ} \mathrm{E}$ longitude. (B) A-A* graphs for the populations. GD percentage in cross $A$ is presented on the vertical axis and GD percentage in cross $\mathrm{A}^{*}$ on the horizontal axis. Each dot represents data for an isofemale line. The number of isofemale lines examined is shown in parentheses. Definition of a line in the P-M system was according to Kidwell (1983) and Quesneville \& Anxolabéhère (1998).
1999). The ratio of KP to full-size $P$ elements of each line (the KP/P ratio) was calculated from the appropriate band densities and pooled by population.

\section{Results}

\section{GD tests for eight populations}

The result of GD tests for each population was shown as a two-dimensional graph, A-A* graph, according to Yamamoto et al. (1984) (Fig. 1). An A-A* graph shows intensities of inducibility and ability to repress $P$ element transposition of the individual isofemale line as a dot. The depiction of the total P-M characteristics of each population as a distribution pattern of dots therefore allows us to compare visually the P-M characteristics of populations.

The Yonaguni (YN) and Taipei (TP) populations contained many $\mathrm{Q}$, some weak $\mathrm{P}$, and only a few weak $\mathrm{M}$ lines; most data appeared from the left-bottom corner to about the middle of the vertical axis in the A-A* graphs. The Ishigaki (IS), Iriomote (IR), and Hateruma (HT) populations contained many $Q$ and variable $\mathrm{P}$ lines; data were distributed along the vertical axis. The Miyako (MY) and Kurima (KR) populations were predominantly $\mathrm{Q}$ with only a few weak $\mathrm{P}$ and weak $\mathrm{M}$ lines; the data clustered at the bottom-left corner in the graphs. The Irabu (IB) lines were also mostly Q, but with one strong $\mathrm{M}$ line, IB-5. Based on the A-A* graphs, the populations were classified into three groups: (1) TP 
and YN; (2) HT, IR and IS; and (3) IB, KR, and MY populations.

The line IR-23 showed more than $10 \%$ GD scores in both crosses $\mathrm{A}(35.5 \%)$ and $\mathrm{A} *(32.8 \%)$. To confirm this result, additional mating experiments were performed (Table 2$)$. The intraline sterility was low $(0.8 \%)$ as well as the results from the reciprocal cross of crosses $\mathrm{A}$ $(4.3 \%)$ and $\mathrm{A}^{*}(6.7 \%)$. Another cross A using Oregon R as an $\mathrm{M}$ standard also showed quite high GD sterility $(34.2 \%)$. These results suggested that the sterility observed in the GD tests was associated with the P-M system, and thus it was an unusual $\mathrm{P}^{\prime}$ type line (Quesneville \& Anxolabéhère, 1998).

\section{Southern blot analysis of each isofemale line}

To analyse the $\mathrm{P}$ element composition of each isofemale line, Southern blot hybridization was carried out. All lines examined had many $\mathrm{P}$ element copies in their genomes (Fig. 2). Accordingly, all $\mathrm{M}$ lines in this area were so-called $\mathrm{M}^{\prime}$ types by definition (Rubin et al., 1982). The $2.2 \mathrm{~kb}$ and $0.4 \mathrm{~kb}$ bands were two of the

Table 2 Sterilities of the IR-23 isofemale line of Drosophila melanogaster

\begin{tabular}{lcc}
\hline Cross* (females $\times$ males) & $\begin{array}{c}\% \\
\text { sterility }\end{array}$ & $\begin{array}{c}\text { No. of } \\
F_{1} \text { females }\end{array}$ \\
\hline Canton S $\times$ IR-23 & 35.5 & 92 \\
IR-23 × Canton S & 4.3 & 58 \\
Harwich $\times$ IR-23 & 6.7 & 52 \\
IR-23 $\times$ Harwich & 32.8 & 67 \\
Oregon R $\times$ IR-23 & 34.2 & 92 \\
IR-23 $\times$ IR-23 & 0.8 & 536 \\
\hline
\end{tabular}

*All crosses were carried out at $29^{\circ} \mathrm{C}$. major signals in the blots, which means that full-size $\mathrm{P}$ and KP elements were two of the major $\mathrm{P}$ elements in these populations. Only one line, KR-7 from Kurima, had no full-size $\mathrm{P}$ element, whereas there was no line completely free of KP elements.

The relative numbers of KP and full-size $\mathrm{P}$ elements in each line was calculated as the $\mathrm{KP} / \mathrm{P}$ ratio. Average ratios for each population were different from island to island (Table 1). In three neighbouring populations, KR (4.15) exhibited approximately twice the value of the MY (2.37) and IB (1.68) lines, despite of their similar data distribution patterns in the $\mathrm{A}-\mathrm{A}^{*}$ graphs. In contrast, there was no statistically significant difference in the average ratios among TP, IS, and MY lines $\left(\chi^{2}=0.00387, P>0.95\right)$, although their A-A* graphs can be distinguished from each other. The total copy number of $\mathrm{P}$ elements in each line was examined by a dot blot, hybridized with the same probe used in the Southern blots. Comparison with a dilution series of genomic DNA from the standard P strain, Harwich, showed that all isofemale lines carried numbers of $\mathrm{P}$ element copies in their genomes comparable to those in Harwich (data not shown). As a result, we could not detect any clear relationship between the genomic $\mathrm{P}$ composition and the P-M phenotypes in these populations.

\section{Discussion}

\section{P-M characteristics of the wild populations in the Sakishima Islands and in Taiwan}

The results of the GD tests for these eight populations were consistent with those of the same populations in the 1980s: showing a predominance of Q type and no obvious geographical clinal pattern in the P-M
Fig. 2 The results of Southern blot hybridization. Genomic DNAs from 69 isofemale lines were digested with $D d e I$ and probed with a 189-bp P element probe. The name of each isofemale line is shown above the lane with the symbol for the individual population (see Table 1); $\mathrm{P}$ types are circled, $\mathrm{M}$ types boxed, and $\mathrm{Q}$ types unmarked. The bands expected from full-size $\mathrm{P}(2.2 \mathrm{~kb})$ and $\mathrm{KP}(0.4 \mathrm{~kb})$ elements are indicated by arrows. CS: Canton S; Hw: Harwich.
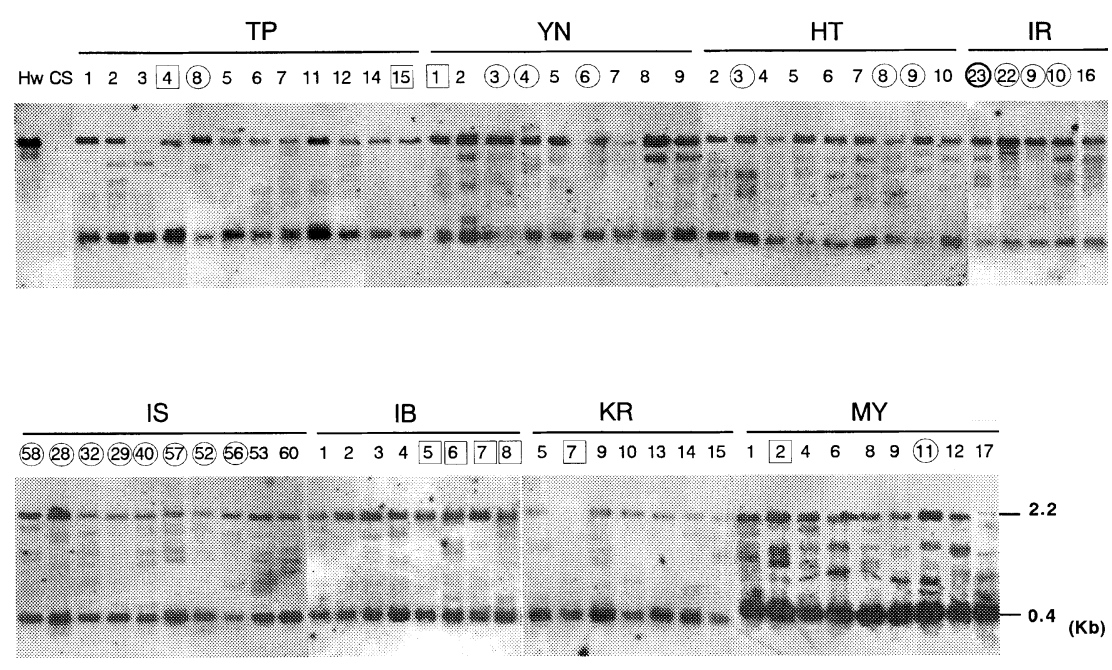

(C) The Genetics Society of Great Britain, Heredity, 86, 206-212. 
phenotypes in this area (Matsuura et al., 1993), although the geographically adjacent populations tend to show similar pattern in the $\mathrm{A}-\mathrm{A}^{*}$ graphs. In addition, Matsuura et al. (1993) reported the P-M characteristics of the Miyako, Ishigaki, and Iriomote populations in the 1980s. Their data points were distributed along the vertical axis in the 1982 and 1984 graphs for the Ishigaki and Iriomote populations and around the left-bottom corner in the 1984 graph for the Miyako population. Therefore, the P-M characteristics in the current IS, IR, and MY lines are essentially the same as those in the 1980s. These results suggest that the P-M characteristics have not greatly changed in these populations in the past 15 years.

A similar stability was recently reported by Bonnivard \& Higuet (1999) who examined many natural populations, collected mainly from Eurasia, and found a great stability in the phenotypes of the P-M system over the same 15 years. They proposed the existence of a 'buffer zone' made up with $\mathrm{Q}$ strains with a strong ability to regulate $\mathrm{P}$ transposition, as an explanation of the observed stability. The Sakishima Islands are at the south end of the chain of Japanese Islands and about $1500 \mathrm{~km}$ away from Kyushu, the southernmost island of four of main islands of Japan, and $125 \mathrm{~km}$ away from Taiwan. The islands are separated from each other by considerable distances. As a result the migration of flies between populations should be highly restricted. It is thus probable that the sea operates like the 'buffer zone' in this area. In a theoretical study of a recurrent $P$ element invasion and an integrated model of regulation, Quesneville \& Anxolabéhère (1998) showed that an isolated population can become any type of strain after $P$ element invasion, and maintain that state stably thereafter. If, however, dysgenic crosses occur by immigration, the end result is the $\mathrm{Q}$ state. A presumptive $\mathrm{P}^{\prime}$ line, IR-23, observed in Iriomote may support the above set of assumptions, since this unusual state cannot be maintained in a population with frequent immigration from neighbours (Quesneville \& Anxolabéhère, 1998). Note that Fig. 1 of Matsuura et al. (1993) showed similar lines in Ishigaki and Iriomote in 1984, although this was not commented on by the authors. Further evidence for the genetic isolation of the Sakishima populations comes from our recent survey of polymorphic chromosomal inversions in this area. The frequencies of some cosmopolitan inversions were quite different among populations (for example, the frequency of $\operatorname{In}(3 R) P$ was $25.0 \%$ in MY, $30.1 \%$ in IS and $70.8 \%$ in IR; data to be presented elsewhere). Together, our present results about populations in the Far East suggests a great stability in natural populations with regard to the P-M system in the Old World (Bonnivard \& Higuet, 1999).
However, the latitudinal cline in P-M phenotypes found in Australian populations in the 1980s had decayed by the early 1990s (Boussy \& Kidwell, 1987; Boussy, 1987; Boussy et al., 1988, 1998; French et al., 1999). This discrepancy could be the result of a difference in the invasion time of $\mathrm{P}$ elements into the populations, or in frequency of migration. We need more information about phenotypic stability in many wild populations over long time periods to solve this problem.

\section{Genomic $P$ elements and the P-M phenotypes in the Sakishima Islands and Taiwan}

All isofemale lines examined carried many $\mathrm{P}$ elements, most of which were full-size P and KP elements. This is consistent with the result of Nitasaka \& Yamazaki (1994), who isolated four full-size $\mathrm{P}$ and two KP elements from 27 clones of genomic $\mathrm{P}$ elements from an Ishigaki strain established in 1980. Comparatively homogeneous genomic $\mathrm{P}$ element profiles were also found in Australian populations (Boussy et al., 1988; Itoh et al., 1999) and in Eurasian, African, East Asia and Oceania-Pacific populations (Bonnivard \& Higuet, 1999). These data demonstrate a number of features of genomic P elements. First, total copy numbers were not very different between populations. In our study, dot blot hybridization detected no major differences in signal strength. Second, the majority of the P element sizes seen were those of entirely full-size $\mathrm{P}$ and $\mathrm{KP}$ elements, as mentioned above. Third, KP elements appeared not as important as full-size $\mathrm{P}$ elements in determination of P-M phenotype, although the KP element was shown to have a repression potential of $\mathrm{P}$ transposition (Black et al., 1987; Jackson et al., 1988; Andrew \& Gloor, 1995; Brookfield, 1996). KP elements were detected in all lines with a wide divergence in the phenotypes, whereas a line with no full-size $\mathrm{P}$ element could not be $\mathrm{P}$ type, for example, KR-7 (M') in this study. A similar result was reported in some inbred lines derived from an $\mathrm{M}^{\prime}$ strain by Biémont et al. (1990), who found an association of the $\mathrm{P}$ cytotype with genomic full-size P elements, but not with KP elements. These results may suggest that if, as is generally believed, any repressive effect of KP elements requires transcription, the amount of KP protein is expected to differ between strains with the same total numbers of KP elements, depending on whether the locations of the elements are adjacent to enhancer sequences in the DNA which stimulate transcription in the germ line.

Between the KP/P ratio and the $\mathrm{P}-\mathrm{M}$ characteristics, a significant relationship was previously reported: the ratio was higher in the order of $\mathrm{M}^{\prime}, \mathrm{Q}$ and $\mathrm{P}$ strains (Boussy et al., 1988; Bonnivard \& Higuet, 1999; Itoh et al., 1999). However, we could not detect any 
significant relationship between the genomic $\mathrm{P}$ composition and the P-M phenotypes in this study. This may be an artifact caused by a small number of populations and/or genetic heterogeneity within the isofemale line used. Nevertheless, we cannot completely rule out an alternative possibility that the causal basis of P-M phenotypes and the dynamics of the $\mathrm{P}$ element in an isolated population may not be the same as those in a large population, because it is plausible that the immigration rate is very low and the founder effect is larger in such small populations.

\section{Acknowledgements}

We thank S.-C. Tsaur for providing the isofemale lines of Taipei. We also thank I.A. Boussy and T.K. Watanabe for various discussion and careful reading the manuscript.

\section{References}

ANDREW, J. D. AND GLOOR, G. B. 1995. A role for the KP leucine zipper in regulating $\mathrm{P}$ element transposition in Drosophila melanogaster. Genetics, 141, 587-594.

ANXOlABÉHÈre, D., NOUAUd, D., PERIQUET, G. AND TCHEN, P. 1985. P-element distribution in Eurasian populations of Drosophila melanogaster: a genetic and molecular analysis. Proc. Natl. Acad. Sci. U.S.A., 82, 5418-5422.

ANXOlABÉHÈre, D., KIDWELl, M. G. AND PERIQUET, G. 1988. Molecular characteristics of diverse populations are consistent with the hypothesis of a recent invasion of Drosophila melanogaster by mobile P elements. Mol. Biol. Evol., 5, $252-269$.

ANXOlabéHère, D., NOUAud, D., PERIQUeT, G. AND TCHEN, P. 1990. The distribution of the P-M system in Drosophila melanogaster strains from the People's Republic of China. Génét. Sél. Évol., 16, 15-26.

BIÉMONT, C., RONSSERAY, S., ANXOlABÉHÈRE, D., IZAEBEL, H. AND GAUTIER, C. 1990. Localization of P elements, copy number regulation, and cytotype determination in Drosophila melanogaster. Genet. Res., 56, 3-14.

BINGHAM, P. M., KIDWELL, M. G. AND RUBIN, G. M. 1982. The molecular basis of P-M hybrid dysgenesis: The role of the $\mathrm{P}$ element, a P-strain-specific transposon family. Cell, 29, 995-1004.

BLACK, D. M., JACKSON, M. S., KIDWELL, M. G. AND DOVER, G. A. 1987. KP elements repress P-induced hybrid dysgenesis in Drosophila melanogaster. EMBOJ., 6, 4125-4135.

BONNIVARD, E. AND HIGUET, D. 1999. Stability of European natural populations of Drosophila melanogaster with regard to the P-M systems: a buffer zone made up of Q populations. J. Evol. Biol., 12, 633-647.

BOUSSY, I. A. 1987. A latitudinal cline in P-M gonadal dysgenesis potential in Australian Drosophila melanogaster populations. Genet. Res., 49, 11-18.

BOUSSY, I. A. AND KIDWELl, M. G. 1987. The P-M hybrid dysgenesis cline in eastern Australian Drosophila melanog- aster: discrete $\mathrm{P}, \mathrm{Q}$ and $\mathrm{M}$ regions are nearly contiguous. Genetics, 115, 737-745.

BOUSSY, I. A., HEALY, M. J., OAKSHOTT, J. G. AND KIDWELL, M. G. 1988. Molecular analysis of the P-M gonadal dysgenesis cline in eastern Australian Drosophila melanogaster. Genetics, 119, 889-902.

BOUSSY, I. A., ITOH, M., RAND, D. AND WOODRUFF, R. C. 1998. Origin and decay of the $\mathrm{P}$ element-associated latitudinal cline in Australian Drosophila melanogaster. Genetica, 104, 45-57.

BROOKFIELD, J. F. Y. 1996. Genetic evidence for repression of somatic P elements in Drosophila melanogaster consistent with a role for the KP element. Heredity, 76, 386-391.

CORISH, P., BLACK, D. M., FEATHERSTON, D. W., MERRIAM, J. AND DOVER, G. A. 1996. Natural repression of P-induced hybrid dysgenesis in Drosophila melanogaster: a model for repressor evolution. Genet. Res., 67, 109-121.

ENGELS, w. R. 1979. Germ line aberrations associated with a case of hybrid dysgenesis in Drosophila melanogaster males. Genet. Res., 33, 137-146.

ENGEls, w. R. 1996. P elements in Drosophila. In: Saedler, H. and Giel, A. (eds) Transposable Elements, pp. 103-123. Springer-Verlag, Berlin.

ENGELS, W. R. AND PRESTON, C. R. 1980. Components of hybrid dysgenesis in a wild population of Drosophila melanogaster. Genetics, 95, 111-128.

FRENCH, D. J., CORISH, P., SHI, M. AND DOVER, G. A. 1999. Evolutionary flux of $\mathrm{P}$ element regulation in a Drosophila melanogaster hybrid dysgenesis cline. Genet. Res., 73, 205-216.

GAMO, S., SAKAJO, M., IKEDA, K., INOUE, Y. H. ET $A$ L. 1990. Temporal distribution of $\mathrm{P}$ elements in Drosophila melanogaster strains from natural populations in Japan. Jap. J. Genet., 65, 277-285.

GLOOR, G. B., PRESTON, C. R., JOHNSON-SCHLITZ, D. M., NASSIF, N. A. ET AL. 1993. Type I repressors of P element mobility. Genetics, 135, 81-95.

HATANO, Y., INOUE, Y., WATADA, M., AKAI, S. M. ET AL. 1999. Further genetic studies on the Katsunuma population of Drosophila melanogaster. Genes Genet. Syst., 74, 219-225.

HOUCK, M. A., CLARK, J. B., PETERSON, K., R. AND KIDWELL, M. G. 1991. Possible horizontal transfer of Drosophila genes by the mite Proctolaelaps regalis. Science, 253, 1125-1129.

HUE, K. AND WANG, Q.-M. 1998. The distributional clines in $\mathrm{P}$ susceptibility causing by the $\mathrm{P}$ family transposable element in Drosophila melanogaster population of China. Acta Genet. Sinica, 25, 213-224.

ITOH, M., WOODRUFF, R. C., LEONE, M. A. AND BOUSSY, I. A. 1999. Genetic P elements and P-M characteristics of eastern Australian populations of Drosophila melanogaster. Genetica, 106, 231-245.

JACKSON, M. S., BLACK, D. M. AND DOVER, G. A. 1988. Amplification of KP elements associated with the repression of hybrid dysgenesis in Drosophila melanogaster. Genetics, 120, 1003-1013.

KARESS, R. E. AND RUBIN, G. M. 1984. Analysis of p transposable element functions in Drosophila. Cell, 38, 135-146. 
KIDWELL, M. G. 1983. Evolution of hybrid dysgenesis determinants in Drosophila melanogaster. Proc. Natl. Acad. Sci. U.S.A., 80, 1655-1169.

KIDWELl, M. G., KIDWELl, J. F. AND SVED, J. A. 1977. Hybrid dysgenesis in Drosophila melanogaster: a syndrome of aberrant traits including mutation, sterility and male recombination. Genetics, 86, 813-833.

LASKI, F. A., RIO, D. C. AND RUBIN, G. M. 1986. Tissue specificity of Drosophila P element transposition is regulated at the level of mRNA splicing. Cell, 44, 7-19.

MATSUURA, E. T., TAKADA, S., KATO, H., NIIZEKI, S. ET AL. 1993. Hybrid dysgenesis in natural populations of Drosophila melanogaster in Japan. III. The P-M System in and around Japan. Genetica, 90, 9-16.

MISRA, S., BURATOWSKI, R. M., OHKAWA, T. AND RIO, D. C. 1993. Cytotype control of Drosophila melanogaster $\mathrm{P}$ element transposition: Genomic position determines maternal repression. Genetics, 135, 785-800.

NITASAKA, E. AND YAMAZAKI, T. 1994. The relationship between DNA structural variation and activities of $\mathrm{P}$ elements in $\mathrm{P}$ and Q strains of Drosophila melanogaster. Heredity, 73, 608-615.

O'HARE, K. AND RUBIN, G. M. 1983. Structure of P transposable elements and their sites of insertion and excision in the Drosophila melanogaster genome. Cell, 34, 25-35.

QUESNEVILle, H. AND ANXOlABÉHÈRE, D. 1998. Dynamics of transposable elements in metapopulations: a model of $\mathrm{P}$ element invasion in Drosophila. Theor. Pop. Biol., 54, 175-193.
RASMUSSON, K. E., RAYMOND, J. D. AND SIMMONS, M. J. 1993. Repression of hybrid dysgenesis in Drosophila melanogaster by individual naturally occurring P elements. Genetics, 133, 606-622.

RIO, D. C., LASKI, F. A. AND RUBIN, G. M. 1986. Identification and immunochemical analysis of biologically active Drosophila $\mathrm{P}$ element transposase. Cell, 44, 21-31.

ROBERTSON, H. M. AND ENGELS, W. R. 1989. Modified P elements that mimic the $\mathrm{P}$ cytotype in Drosophila melanogaster. Genetics, 123, 815-824.

RUBIN, G. M., KIDWELl, M. G. AND BINGHAM, P. M. 1982. The molecular basis of P-M hybrid dysgenesis: The nature of induced mutations. Cell, 29, 987-994.

SAKOYAMA, Y., TODO, T., ISHIWA-CHIGUSA, S. AND KONDO, S. 1985. Structures of defective $P$ transposable elements prevalent in natural Q and Q-derived M strains of Drosophila melanogaster. Proc. Natl. Acad. Sci. U.S.A., 82, 6232-6239.

SIMMONS, M. J., RAYMOND, J. D., GRIMES, C. D., BELINCO, C. ET AL. 1996. Repression of hybrid dysgenesis in Drosophila melanogaster by heat-shock inducible sense and antisense P-element constructs. Genetics, 144, 1529-1544.

todo, T., SAkoyama, Y., ChiguSa, S. I., Fukunaga, A. $E T A L$. 1984. Polymorphism in distribution and structure of $\mathrm{P}$ elements in natural populations of Drosophila melanogaster in and around Japan. Jap. J. Genet., 59, 441-451.

YAMAMOTO, A., HIHARA, F. AND WATANABE, T. K. 1984. Hybrid dysgenesis in Drosophila melanogaster: predominance of Q factor in Japanese populations and its change in the laboratory. Genetica, 63, 71-77. 